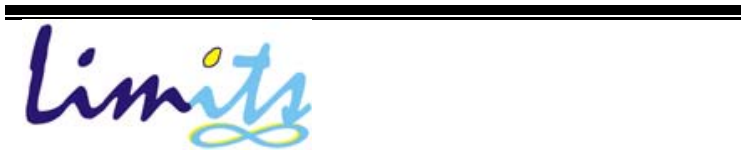

Limits: Journal of Mathematics and Its Applications

E-ISSN: 2579-8936

P-ISSN: $1829-605 \mathrm{X}$

Vol. 17, No. 1, Juli 2020, 1-8

DOI: http://dx.doi.org/10.12962/limits.v17i1.6030

\title{
Kategori Modul yang Dibangun oleh $\boldsymbol{u}_{\boldsymbol{V}}$
}

\author{
Fitriani $^{1 *}$, Ahmad Faisol ${ }^{2}$ \\ ${ }^{1,2}$ Jurusan Matematika FMIPA Universitas Lampung \\ Bandar Lampung, Lampung, Indonesia \\ e-mail:' fitriani.1984@fmipa.unila.ac.id, ${ }^{2}$ ahmadfaisol@fmipa.unila.ac.id \\ Diajukan:22 Oktober 2019, Diperbaiki: 27 Januari 2020, Diterima:23 Mei 2020
}

\begin{abstract}
Abstrak
Misalkan $\mathcal{U}$ keluarga modul atas $R$ dan $V$ merupakan submodul dari jumlah langsung beberapa elemen di dalam keluarga $\mathcal{U}$. Modul $N$ atas $R$ dibangun oleh $\mathcal{U}_{V}$ jika terdapat epimorfisma dari $V$ ke $N$. Modul yang dibangun oleh $\mathcal{U}_{V}$ merupakan perumuman dari modul yang dibangun oleh $\mathcal{U}$. Perumuman ini dilakukan dengan menggunakan konsep barisan $V$-koeksak dari modul. Di dalam paper ini, dikonstruksi kategori dari modul-modul yang dibangun oleh $\mathcal{U}_{V}$ beserta beberapa sifat-sifatnya. Selain itu, ditunjukkan bahwa kategori modul yang dibangun oleh $\mathcal{U}_{V}$ merupakan kategori pre-aditif.
\end{abstract}

Kata Kunci: $\mathcal{U}_{V}$-generator, barisan $V$-koeksak, kategori pre-aditif, $\mathcal{U}$-generator.

Abstract

Let $\mathcal{U}$ be a family of $R$-modules and $V$ be a submodule of a direct sum of some elements in $U$. An $R$ module $N$ is generated by $\mathcal{U}_{V}$ if there exists an epimorphism from $V$ to $N$. The notion of the $\mathcal{U}_{V}$-generated module is a generalization of the $U$-generated module. This generalization uses the concept of the $V$ coexact sequence of modules. In this paper, we construct a category of $u_{V}$-generated modules. Furthermore, we investigate some properties of the category of $\mathcal{U}_{V}$-generated modules. We also prove that this category is a pre-additive category.

Keywords: $U_{V}$-generator, $V$-coexact sequence, category pre-additive, $U$-generator.

\section{Pendahuluan}

Barisan eksak merupakan salah satu konsep penting di dalam struktur aljabar. Misalkan $K$, $L, M$ merupakan modul-modul atas $\operatorname{ring} R$ dan $f, g$ merupakan homomorfisma modul atas $R$. Barisan homomorfisma modul atas ring $R$

$$
K \stackrel{f}{\rightarrow} L \stackrel{g}{\rightarrow} M
$$

dikatakan eksak jika $\operatorname{Im}(f)=\operatorname{Ker}(g)$ [1]. Barisan eksak ini diperumum oleh Davvaz dan Parnian-Garamaleky [2] yang dilakukan dengan cara mengganti submodul 0 dengan sebarang submodul $U$ di $M$. Mereka memperumum beberapa konsep terkait dengan barisan eksak yang diperumum menjadi barisan $U$-eksak dan mendefinisikan barisan $V$-koeksak sebagai dual dari barisan $U$-eksak. Selain itu, di dalam [3] Davvaz dkk. memberikan perumuman beberapa konsep 
dalam aljabar homologi menggunakan konsep barisan quasi eksak dan di dalam [4], Anvariyeh dkk. memperkenalkan barisan $U$-terpisah serta kaitan antara barisan $U$-terpisah dan modul proyektif.

Selanjutnya, di dalam [5] Davvaz dan Anvariyeh memberikan hasil lanjutan mengenai barisan quasi eksak dan menggunakannya untuk memperumum Lemma Schanuel dan Madanshekaf [6] menggunakan barisan $U$-eksak dalam mengembangkan konsep presentasi berhingga dari modul atas $R$ dan fungtor torsi dalam kategori $R$-MOD.

Selanjutnya, sebagai aplikasi dari barisan $U$-eksak, Aminizadeh [7] menggunakan konsep barisan $U$-eksak untuk memperkenalkan barisan $U$-eksak dari $S$-act. Selain itu, Elviyanti dkk. [8] mengkonstruksi kategori $U$-kompleks dengan menggunakan konsep barisan $U$-eksak. Pada tahun 2017, Mahatama dan Muchtadi-Alamsyah [9] mengkonstruksi U-resolusi proyektif yang merupakan perumuman dari resolusi proyektif suatu modul dengan menggunakan konsep barisan U-eksak.

Termotivasi dari pendefinisian barisan $U$-eksak dan barisan $V$-koeksak, Fitriani dkk. [10] mendefinisikan barisan $X$-sub-eksak sebagai perumuman barisan eksak. Konsep ini digunakan dalam perumuman dari keluarga modul bebas linear. Keluarga modul bebas linear ini merupakan perumuman dari himpunan bebas linear [1]. Selain itu, Fitriani dkk. [11] memperumum keluarga $\mathcal{U}$-generator dengan menggunakan konsep barisan $V$-koeksak. Selanjutnya, Fitriani dkk. [12] memperumum konsep basis dan modul bebas menggunakan konsep keluarga modul $X$-sub bebas linear dan keluarga $\mathcal{U}_{V}$-generator. Di dalam penelitian ini, dikonstruksi kategori yang obyeknya adalah modul-modul yang dibangun oleh $\mathcal{U}_{V}$ dan akan diselidiki sifat-sifatnya. Hasil-hasil pada penelitian ini selanjutnya akan digunakan untuk mendefinisikan rank dari suatu modul yang dibangun oleh $U_{V}$ yang merupakan perumuman dari rank modul di dalam kategori modul atas $R$.

\section{Metode Penelitian}

Penelitian ini dilakukan dengan langkah-langkah sebagai berikut:

1. Mengkonstruksi kategori modul yang dibangun oleh $\mathcal{U}_{V}$ yang selanjutnya dinotasikan dengan $\mu\left(\mathcal{U}_{\mathrm{V}}\right)$;

2. Menyelidiki sifat-sifat kategori $\mu\left(\mathcal{U}_{\mathrm{V}}\right)$;

3. Menyelidiki sifat pre-aditif pada kategori $\mu\left(\mathcal{U}_{\mathrm{V}}\right)$. . 


\section{Hasil dan Pembahasan}

Pada bagian ini akan diberikan hasil-hasil penelitian yang meliputi konstruksi kategori $\mu\left(\mathcal{U}_{\mathrm{V}}\right)$, pembuktian sifat-sifat kategori $\mu\left(\mathcal{U}_{\mathrm{V}}\right)$ dan uraian mengenai sifat pre-aditif pada kategori $\mu\left(\mathcal{U}_{\mathrm{V}}\right)$. Untuk selanjutnya, yang dimaksud dengan $\mathcal{U}$ adalah keluarga modul atas ring $R$ dan $V$ merupakan submodul dari $\oplus_{\Lambda} U_{\lambda}$, dengan $U_{\lambda} \in \mathcal{U}$, untuk setiap $\lambda \in \Lambda$.

\section{1. Konstruksi Kategori $\mu\left(\mathcal{U}_{\mathrm{V}}\right)$}

Misalkan $\mathcal{U}=\left\{U_{\lambda}\right\}_{\Lambda}$ keluarga modul atas ring $R$. Modul $M$ dibangun oleh $\mathcal{U}$ jika terdapat epimorfisma dari $\bigoplus_{\Lambda} U_{\lambda}$ ke $M[13]$. Konsep $\mathcal{U}$-generator ini diperumum menjadi $\mathcal{U}_{V}$-generator. Hal ini dilakukan dengan cara mengganti $\bigoplus_{\Lambda} U_{\lambda}$ dengan sebarang submodulnya. Misalkan $V$ submodul $\oplus_{\Lambda} U_{\lambda}$. Suatu modul $N$ dikatakan dibangun oleh $U_{V}$ jika terdapat epimorfisma dari $V$ ke $N$ [11]. Jika diambil $V=\bigoplus_{\Lambda} U_{\lambda}$, maka $\mathcal{U}_{V}$-generator merupakan $U$-generator. Oleh karena itu, $\mathcal{U}$-generator merupakan kasus khusus dari $\mathcal{U}_{V}$-generator. Hal ini dijelaskan sebagai berikut. Diberikan modul $M$ yang merupakan modul $\mathcal{U}$-generator. Hal ini berarti terdapat epimorfisma $f: \bigoplus_{\Lambda} U_{\lambda} \rightarrow M$. Karena $\bigoplus_{\Lambda} U_{\lambda}$ merupakan submodul dari dirinya sendiri, dapat diambil $V=\oplus_{\Lambda} U_{\lambda}$. Akibatnya, terdapat epimorfisma dari $V$ ke $M$ yang berarti $M$ merupakan modul $U_{V^{-}}$ generator. Oleh karena itu, setiap modul $\mathcal{U}$-generator merupakan modul $\mathcal{U}_{V}$-generator.

Hal ini tidak berlaku sebaliknya, yaitu setiap modul $\mathcal{U}_{V}$-generator belum tentu merupakan modul $\mathcal{U}$-generator. Sebagai contoh, jika $\mathcal{U}=\{\mathbb{Q}\}$ kelas modul atas bilangan bulat $\mathbb{Z}$, dengan $\mathbb{Q}$ himpunan bilangan rasional dan $M=\mathbb{Z}$ sebagai modul atas $\mathbb{Z}$. Karena tidak terdapat epimorfisma dari $\mathbb{Q}$ ke $\mathbb{Z}$, modul $M$ bukan merupakan modul $\mathcal{U}$-generator. Jika diambil $\mathrm{V}=\mathbb{Z}$ yang merupakan submodul $\mathbb{Q}$, maka jelas bahwa terdapat epimorfisma dari $V$ ke $M$. Hal ini berakibat $M$ merupakan modul $U_{\mathbb{Z}}$-generator. Hal ini menunjukkan bahwa $\mathcal{U}$-generator merupakan kasus khusus dari $\mathcal{U}_{V}$-generator.

Kelas modul-modul yang dibangun oleh $\mathcal{U}_{V}$ dinotasikan dengan $\mu\left(\mathcal{U}_{\mathrm{V}}\right)$. Dalam proposisi berikut dibuktikan bahwa $\mu\left(\mathcal{U}_{\mathrm{V}}\right)$ merupakan suatu kategori.

Proposisi 1. Kelas modul-modul yang dibangun oleh $\mathcal{U}_{V}$, yaitu $\mu\left(\mathcal{U}_{\mathrm{V}}\right)$ merupakan suatu kategori.

\section{Bukti.}

1. Obyek: kelas dari semua modul yang dibangun oleh $\mathcal{U}_{V}$, yang dapat dituliskan sebagai berikut:

$$
\operatorname{Obj}\left(\mu\left(\mathcal{U}_{\mathrm{V}}\right)\right)=\left\{M \in R-M O D \mid M \text { dibangun oleh } \mathcal{U}_{\mathrm{V}}\right\}
$$


dengan $R-M O D$ merupakan kategori modul atas ring $R$. Jika $M$ termuat di dalam $\operatorname{Obj}\left(\mu\left(\mathcal{U}_{\mathrm{V}}\right)\right)$, maka $M$ dibangun oleh $\mathcal{U}_{\mathrm{V}}$ yang artinya terdapat epimorfisma $f$ dari $V$ ke $M$.

2. Morfisma: morfisma di dalam kategori $\mu\left(\mathcal{U}_{\mathrm{V}}\right)$ adalah morfisma modul atas $R$. Misalkan $K, L \in \operatorname{Obj}\left(\mu\left(\mathcal{U}_{\mathrm{V}}\right)\right)$. Morfisma $\operatorname{Mor}_{\mu\left(U_{\mathrm{V}}\right)}(K, L)$ adalah himpunan $\operatorname{Mor}_{\mu\left(U_{\mathrm{V}}\right)}(K, L)=\{f: K \rightarrow L \mid f$ homomorfisma modul atas $R\}$.

3. Komposisi Morfisma: komposisi morfisma di dalam kategori $\mu\left(\mathcal{U}_{\mathrm{V}}\right)$ adalah komposisi morfisma modul atas $R$ yang memenuhi:

a. Untuk setiap modul-modul atas $R$ yaitu $K, L, M, N$ yang termuat di dalam $\operatorname{Obj}\left(\mu\left(U_{\mathrm{V}}\right)\right)$ dan $f \in \operatorname{Mor}_{\mu\left(U_{\mathrm{V}}\right)}(K, L), g \in \operatorname{Mor}_{\mu\left(u_{\mathrm{V}}\right)}(L, M), h \in \operatorname{Mor}_{\mu\left(U_{\mathrm{V}}\right)}(M, N)$, berlaku $f \circ(g \circ h)=(f \circ g) \circ h$.

b. Untuk setiap $M \in \operatorname{Obj}\left(\mu\left(\mathcal{U}_{\mathrm{V}}\right)\right)$, terdapat morfisma $i d_{M} \in \operatorname{Mor}_{\mu\left(\mathcal{V}_{\mathrm{V}}\right)}(M, M)$ yang memenuhi $f \circ i d_{M}=i d_{N} \circ f, \quad$ untuk setiap $f \in \operatorname{Mor}_{\mu\left(u_{\mathrm{V}}\right)}(M, N), \quad N \in$ $\operatorname{Obj}\left(\mu\left(\mathcal{U}_{\mathrm{V}}\right)\right)$.

Berdasarkan uraian tersebut, $\mu\left(\mathcal{U}_{\mathrm{V}}\right)$ merupakan suatu kategori.

Berdasarkan [13], suatu kategori $\mathcal{D}$ merupakan subkategori $\mathcal{C}$ jika memenuhi:

a. $\operatorname{Obj}(\mathcal{D}) \subseteq \operatorname{Obj}(\mathcal{C})$,

b. $\operatorname{Mor}_{\mathcal{D}}(A, B) \subseteq \operatorname{Mor}_{\mathcal{C}}(A, B)$, untuk setiap $A, B \in \operatorname{Obj}(\mathcal{D})$,

c. Komposisi morfisma di $\mathcal{D}$ merupakan pembatasan dari komposisi morfisma di $\mathcal{C}$.

Jika $\operatorname{Mor}_{\mathcal{D}}(A, B)=\operatorname{Mor}_{\mathcal{C}}(A, B)$, maka $\mathcal{D}$ dikatakan subkategori penuh dari $\mathcal{C}$ [13]. Jika dibandingkan dengan kategori modul atas ring $R$, yaitu $R$-MOD, kategori $\mu\left(\mathcal{U}_{\mathrm{V}}\right)$ merupakan subkategori penuh dari $R$-MOD seperti diberikan dalam proposisi berikut.

Proposisi 2. Kategori modul yang dibangun oleh $\mathcal{U}_{\mathrm{V}}$, yaitu $\mu\left(\mathcal{U}_{\mathrm{V}}\right)$ adalah subkategori penuh dari $R-M O D$ yang merupakan kategori modul atas ring $R$.

Bukti. Pada konstruksi kategori $\mu\left(\mathcal{U}_{\mathrm{V}}\right)$ terlihat bahwa $\operatorname{Obj}\left(\mu\left(\mathcal{U}_{\mathrm{V}}\right)\right) \subset \operatorname{Obj}(R-M O D)$ dan $\operatorname{Mor}_{\mu\left(U_{\mathrm{V}}\right)}(M, N)=\operatorname{Mor}_{R-M O D}(M, N)$. Oleh karena itu, terbukti bahwa $\mu\left(\mathcal{U}_{\mathrm{V}}\right)$ adalah subkategori penuh dari $R-\mathrm{MOD}$.

\section{2. Beberapa Sifat Kategori $\mu\left(\mathcal{U}_{\mathrm{V}}\right)$}

Pada bagian ini diberikan beberapa sifat kategori $\mu\left(\mathcal{U}_{\mathrm{V}}\right)$. Beberapa sifat modul yang dibangun oleh $\mathcal{U}_{\mathrm{V}}$ telah diberikan di dalam [11]. Berikut ini diberikan sifat kategori $\mu\left(\mathcal{U}_{\mathrm{V}}\right)$ yang menyatakan bahwa kategori ini tertutup terhadap image homomorfisma sebagai berikut. 
Proposisi 3. Jika $M \in \operatorname{Obj}\left(\mu\left(\mathcal{U}_{\mathrm{V}}\right)\right)$, maka $N \in \operatorname{Obj}\left(\mu\left(\mathcal{U}_{\mathrm{V}}\right)\right.$, untuk setiap image homomorfisma $N$ dari $M$.

Bukti. Diberikan sebarang $M \in \operatorname{Obj}\left(\mu\left(\mathcal{U}_{\mathrm{V}}\right)\right)$. Hal ini berarti modul $M$ atas $R$ dibangun oleh $\mathcal{U}_{\mathrm{V}}$. Oleh karena itu, terdapat epimorfisma $f$ dari $V$ ke $M$. Misalkan $N$ adalah image homomorfisma $f$ dari $M$, yang berarti $\operatorname{im}(f)=N$. Akibatnya, $f$ merupakan suatu epimorfisma dari $M$ ke $N$. Jadi, $g \circ f$ merupakan epimorfisma dari $V$ ke $N$. Jadi, $N$ merupakan modul yang dibangun oleh $U_{\mathrm{V}}$. Dengan kata lain, $N \in \operatorname{Obj}\left(\mu\left(\mathcal{U}_{\mathrm{V}}\right)\right)$ yang menunjukkan bahwa kategori $\mu\left(\mathcal{U}_{\mathrm{V}}\right)$ tertutup terhadap image homomorfisma.

Misalkan $M$ merupakan modul yang dibangun oleh $\mathcal{U}_{\mathrm{V}}$. Karena terdapat pemetaan nol yang merupakan epimorfisma dari $M$ ke modul 0 , modul 0 merupakan image homomorfisma dari setiap modul yang dibangun oleh $\mathcal{U}_{\mathrm{V}}$. Oleh karena itu, berdasarkan Proposisi 3 diperoleh bahwa $0 \in \operatorname{Obj}\left(\mu\left(\mathcal{U}_{\mathrm{V}}\right)\right)$. Demikian halnya dengan modul faktor dari modul yang dibangun oleh $\mathcal{U}_{\mathrm{V}}$ seperti diberikan dalam sifat berikut.

Akibat 4. Jika $M \in \operatorname{Obj}\left(\mu\left(\mathcal{U}_{\mathrm{V}}\right)\right)$, maka $M / N \in \operatorname{Obj}\left(\mu\left(\mathcal{U}_{\mathrm{V}}\right)\right.$, untuk setiap modul faktor $M / N$ dari $M$.

Bukti. Diberikan sebarang modul faktor $M / N$ dari $M$. Oleh karena itu, terdapat pemetaan proyeksi kanonik $p: M \rightarrow M / N$. Jadi, berdasarkan Proposisi 3 diperoleh $M / N \in \operatorname{Obj}\left(\mu\left(\mathcal{U}_{\mathrm{V}}\right)\right.$, untuk setiap modul faktor $M / N$ dari $M$.

Selanjutnya, dari [11, Proposisi 9] diperoleh bahwa jika $N_{\alpha}$ dibangun oleh $\mathcal{U}_{V_{\alpha}}$, untuk setiap $\alpha \in A$, maka $\oplus_{A} N_{\alpha}$ dibangun oleh $U_{\oplus_{A} V_{\alpha}}$. Akibatnya, diperoleh sifat berikut.

Akibat 5. Jika $M_{\alpha} \in \operatorname{Obj}\left(\mu\left(\mathcal{U}_{\mathrm{V}_{\alpha}}\right)\right)$, untuk setiap $\alpha \in A$, maka $\oplus_{A} M_{\alpha} \in \operatorname{Obj}\left(\mu\left(\mathcal{U}_{\oplus_{A} V_{\alpha}}\right)\right.$.

Bukti. Diberikan $M_{\alpha} \in \operatorname{Obj}\left(\mu\left(\mathcal{U}_{\mathrm{V}_{\alpha}}\right)\right.$ ), untuk setiap $\alpha \in A$. Hal ini berakibat terdapat epimorfisma $f_{\alpha}: V_{\alpha} \rightarrow M_{\alpha}$, untuk setiap $\alpha \in A$. Oleh karena itu, dapat dibentuk $\bigoplus_{A} f_{\alpha}: \bigoplus_{A} V_{\alpha} \rightarrow$ $\oplus_{A} M_{\alpha}$. Karena masing-masing $f_{\alpha}$ merupakan epimorfisma, diperoleh $\oplus_{A} f_{\alpha}$ epimorfisma. Oleh karena itu, berdasarkan [11, Proposisi 9], diperoleh $\oplus_{A} M_{\alpha}$ dibangun oleh $\mathcal{U}_{\oplus_{A} V_{\alpha}}$ dan akibatnya $\oplus_{A} M_{\alpha} \in \operatorname{Obj}\left(\mu\left(\mathcal{U}_{\oplus_{A} V_{\alpha}}\right)\right.$.

\section{3. Sifat Pre-Aditif pada Kategori $\mu\left(\mathcal{U}_{\mathrm{V}}\right)$}

Pada bagian ini akan ditunjukkan bahwa $\mu\left(\mathcal{U}_{\mathrm{V}}\right)$ merupakan kategori pre-aditif. Berdasarkan [14, Definisi 1.1], suatu kategori $\mathcal{A}$ dikatakan aditif jika memenuhi kondisi berikut.

1. Untuk setiap pasangan obyek $X$ dan $Y$, himpunan morfisma $\operatorname{Hom}_{\mathcal{A}}(X, Y)$ merupakan grup komutatif dan komposisi morfisma 


$$
\operatorname{Hom}_{\mathcal{A}}(Y, Z) \times \operatorname{Hom}_{\mathcal{A}}(X, Y) \rightarrow \operatorname{Hom}_{\mathcal{A}}(X, Z)
$$

bilinear.

2. Kategori $\mathcal{A}$ memuat obyek 0 , yaitu untuk setiap obyek $X \in \mathcal{A}$, masing-masing himpunan morfisma $\operatorname{Hom}_{\mathcal{A}}(X, 0)$ dan $\operatorname{Hom}_{\mathcal{A}}(0, X)$ memiliki tepat satu elemen.

3. Untuk setiap pasangan obyek-obyek $X, Y$ di $\mathcal{A}$, terdapat ko-hasil kali $X \oplus Y$ di $\mathcal{A}$.

Jika hanya terpenuhi kondisi 1 dan 2 , maka kategori $\mathcal{A}$ disebut kategori pre-aditif [14]. Pada teorema berikut ditunjukkan bahwa kategori $\mu\left(\mathcal{U}_{\mathrm{V}}\right)$ merupakan kategori pre-aditif.

Teorema 6. Kategori $\mu\left(\mathcal{U}_{\mathrm{V}}\right)$ merupakan kategori pre-aditif.

\section{Bukti.}

1. Diberikan sebarang $M, N \in \mu\left(\mathcal{U}_{\mathrm{V}}\right)$. Didefinisikan operasi pada himpunan morfisma $\operatorname{Hom}_{\mathcal{A}}(M, N)$ di dalam kategori $\mu\left(\mathcal{U}_{\mathrm{V}}\right)$ sebagai berikut.

$$
\begin{gathered}
+: \operatorname{Hom}_{\mathcal{A}}(M, N) \times \operatorname{Hom}_{\mathcal{A}}(M, N) \rightarrow \operatorname{Hom}_{\mathcal{A}}(M, N) \\
(f, g) \mapsto f+g,
\end{gathered}
$$

dengan $(f+g)(x)=f(x)+g(x)$, untuk setiap $x \in M$. Dengan definisi ini dapat ditunjukkan bahwa $\left(\operatorname{Hom}_{\mathcal{A}}(M, N),+\right)$ merupakan grup dengan elemen identitas adalah pemetaan nol dan invers dari $f \in \operatorname{Hom}_{\mathcal{A}}(M, N)$ adalah $-f \in \operatorname{Hom}_{\mathcal{A}}(M, N)$. Karena

$$
(f+g)(m)=f(m)+g(m)=g(m)+f(m)=(g+f)(m),
$$

untuk setiap $m \in M,\left(\operatorname{Hom}_{\mathcal{A}}(M, N),+\right)$ merupakan grup komutatif.

Selanjutnya, diberikan sebarang $K, L, M \in \operatorname{Obj}\left(\mu\left(\mathcal{U}_{\mathrm{V}}\right)\right)$. Akan ditunjukkan komposisi morfisma:

$$
\begin{gathered}
+: \operatorname{Hom}_{\mathcal{A}}(L, M) \times \operatorname{Hom}_{\mathcal{A}}(K, L) \rightarrow \operatorname{Hom}_{\mathcal{A}}(K, M) \\
(f, g) \mapsto f \circ g,
\end{gathered}
$$

bersifat bilinear, yaitu untuk setiap $k \in K$, berlaku

$$
\begin{aligned}
\text { a. }((f+g) \circ h)(k) & =(f+g)(h(k)) \\
& =f(h(k))+g(h(k)) \\
& =(f \circ h)(k)+(g \circ h)(k), \\
\text { b. }(f \circ(g+h))(k) & =f((g+h)(k)) \\
& =f(g(k)+h(k)) \\
& =(f \circ g)(k)+(f \circ h)(k) .
\end{aligned}
$$

Oleh karena itu, komposisi morfisma pada kategori $\mu\left(\mathcal{U}_{\mathrm{V}}\right)$ bersifat bilinear.

2. Obyek 0 di dalam kategori $\mu\left(\mathcal{U}_{\mathrm{V}}\right)$ adalah modul 0 dan pada Bagian 3.2 telah diuraikan bahwa modul 0 termuat di dalam kategori $\mu\left(\mathcal{U}_{\mathrm{V}}\right)$. 
Jadi, terbukti bahwa $\mu\left(\mathcal{U}_{\mathrm{V}}\right)$ merupakan kategori pre-aditif.

Selanjutnya, berdasarkan $[11,2.2]$ diperoleh bahwa jika $M, N \in \operatorname{Obj}\left(\mu\left(\mathcal{U}_{\mathrm{V}}\right)\right)$, maka belum tentu $M \oplus N$ termuat di dalam himpunan $\operatorname{Obj}\left(\mu\left(\mathcal{U}_{\mathrm{V}}\right)\right)$. Oleh karena itu, kategori $\mu\left(\mathcal{U}_{\mathrm{V}}\right)$ bukan merupakan kategori aditif.

\section{Simpulan}

Berdasarkan hasil dan pembahasan yang telah diuraikan, diperoleh bahwa himpunan semua modul yang dibangun oleh $\mathcal{U}_{\mathrm{V}}$ membentuk suatu kategori $\mu\left(\mathcal{U}_{\mathrm{V}}\right)$. Kategori ini merupakan subkategori penuh dari kategori modul atas ring $R$, yaitu $R$-MOD. Selain itu, kategori $\mu\left(U_{\mathrm{V}}\right)$ tertutup terhadap image homomorfisma. Hasil ini berakibat modul 0 termuat di dalam kategori $\mu\left(\mathcal{U}_{\mathrm{V}}\right)$ dan untuk setiap $M$ yang termuat di dalam kategori $\mu\left(\mathcal{U}_{\mathrm{V}}\right)$ berakibat modul faktor $M$, yaitu $M / N$ juga termuat di dalam kategori tersebut. Selanjutnya, telah dibuktikan bahwa kategori $\mu\left(\mathcal{U}_{\mathrm{V}}\right)$ merupakan kategori pre-aditif.

\section{Daftar Pustaka}

[1] W. A. Adkins and S. H. Weintraub, Algebra, An Approach via Module Theory. New York: Springer-Verlag, 1992.

[2] B. Davvaz and Y. A. Parnian-Garamaleky, “A Note on Exact Sequences,” Bull. Malaysian Math. Soc., vol. 22, pp. 53-56, 1999.

[3] B. Davvaz and H. Shabani-Solt, “A generalization of homological algebra," J. Korean Math. Soc., vol. 39, no. 6, pp. 881-898, 2002.

[4] S. M. Anvanriyeh and B. Davvaz, "U-Split Exact Sequences," Far East J. Math. Sci., vol. 4, no. 2, pp. 209-219, 2002.

[5] B. Davvaz and S. M. Anvariyeh, "On Quasi Exact Sequences,” Bull. Korean Math. Soc., vol. 42, no. 1, pp. 149-155, 2005.

[6] A. Madanshekaf, "Quasi-Exact Sequence and Finitely Presented Modules," Iran. J. Math. Sci. Informatics, vol. 3, no. 2, pp. 49-53, 2008.

[7] R. Aminizadeh, H. Rasouli, and A. Tehranian, "Quasi-exact Sequences of S-Act,” Bull. Malaysian Math. Soc., 2017.

[8] G. Elfiyanti, I. Muchtadi, D. Nasution, and U. Amartiwi, "Abelian Property of the Category of U-Complexes Chain of U-Complexes," Int. J. Math. Anal., vol. 10, no. 17, pp. 849-853, 2016. 
[9] Y. Mahatma and I. Muchtadi-alamsyah, "Construction of U -extension module," AIP Conf. Proc. 1867, vol. 020025, no. August, 2017.

[10] Fitriani, B. Surodjo, and I. E. Wijayanti, “On Sub-Exact Sequences," Far East J. Math. Sci., vol. 100, no. 7, pp. 1055-1065, 2016.

[11] Fitriani, I. E. Wijayanti, and B. Surodjo, "Generalization of U -Generator and M Subgenerator Related to Category $\sigma$ [ M ]," J. Math. Res., vol. 10, no. 4, pp. 101-106, 2018.

[12] Fitriani, I. E. Wijayanti, and B. Surodjo, "A Generalization of Basis and Free Modules Relatives to a Family of R-Modules," J. Phys. Conf. Ser., vol. 1097, no. 1, 2018.

[13] R. Wisbauer, Foundations of Module and Ring Theory. Philadelphia, USA: Gordon and Breach Science, 1991.

[14] R. R. T. Holm, P. Jorgensen, Triagulated Categories. USA: Cambridge University Press. 